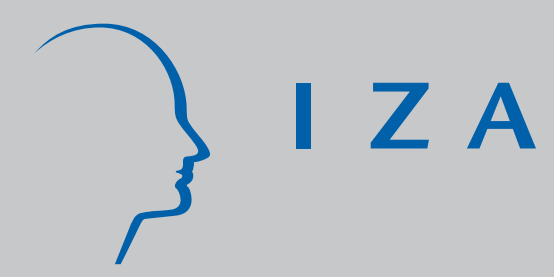

IZA DP No. 1256

Do Financial Incentives Promote the Employment of the Disabled?

Sher Verick

August 2004 


\title{
Do Financial Incentives Promote the Employment of the Disabled?
}

\author{
Sher Verick \\ IZA Bonn \\ and University of Bonn
}

\section{Discussion Paper No. 1256 \\ August 2004}

\author{
IZA \\ P.O. Box 7240 \\ 53072 Bonn \\ Germany \\ Phone: +49-228-3894-0 \\ Fax: +49-228-3894-180 \\ Email: iza@iza.org
}

\begin{abstract}
Any opinions expressed here are those of the author(s) and not those of the institute. Research disseminated by IZA may include views on policy, but the institute itself takes no institutional policy positions.

The Institute for the Study of Labor (IZA) in Bonn is a local and virtual international research center and a place of communication between science, politics and business. IZA is an independent nonprofit company supported by Deutsche Post World Net. The center is associated with the University of Bonn and offers a stimulating research environment through its research networks, research support, and visitors and doctoral programs. IZA engages in (i) original and internationally competitive research in all fields of labor economics, (ii) development of policy concepts, and (iii) dissemination of research results and concepts to the interested public.
\end{abstract}

IZA Discussion Papers often represent preliminary work and are circulated to encourage discussion. Citation of such a paper should account for its provisional character. A revised version may be available directly from the author. 
IZA Discussion Paper No. 1256

August 2004

\section{ABSTRACT}

\section{Do Financial Incentives Promote the Employment of the Disabled?*}

In October 1999 the unemployment rate of people with severe disabilities in Germany was more than double that of the non-disabled population. To improve this situation, the People with Severe Disabilities Act was reformed to increase incentives for the severely disabled to enter the work force and for employers to hire such workers. In 2003 the Federal Government announced that through this reform it had successfully reduced the number of unemployed by $25 \%$ representing around 45,000 individuals. However, an evaluation of the impact of this policy reform on labour market outcomes for the severely disabled indicates that this was not achieved by getting these individuals into employment. Moreover, a recent deterioration in the number of unemployed suggests that the success in 2002 was at best temporary. Thus, there is no evidence that changes to financial incentives in the PSDA had a positive long-term impact on the employment of people with severe disabilities.

JEL Classification: C13, I12, I18, J22, J23

Keywords: disability legislation, policy evaluation, labour market outcomes

Sher Verick

IZA Bonn

P.O. Box 7240

53072 Bonn

Germany

Email: verick@iza.org

\footnotetext{
${ }^{*}$ Financial support from IZA and the Deutsche Forschungsgemeinschaft (DFG) is gratefully acknowledged.
} 


\section{Introduction}

The employment situation of people with disabilities is typically worse than that of the non-disabled population. On average only $30-40 \%$ of disabled workers participate in the labour force compared to around two-thirds for the non-disabled (Delsen 1996). This low rate of employment is a consequence of two factors: firstly, the higher unemployment rate among the disabled, on average around $80 \%$ more than the rate for the non-disabled; and secondly, the higher rates of inactivity for people with disabilities (OECD 2003). Moreover, the duration of unemployment is longer for this group with many of them being long-term unemployed. Important factors that reduce the incentives for employers to hire disabled workers include the costs of accommodating disabled workers, such as those arising from the installation of special equipment and facilities, their (actual or perceived) lower productivity, special dismissal protection, lack of information and discrimination. People with disabilities also face a number of hurdles in accessing the labour market, such as the lack of education and training, lower job mobility, and poor motivation. Given the private costs of exclusion and the social costs of not integrating people with disabilities into mainstream employment, governments have tried to improve this situation via legislation and policies targeting this group.

In some countries such as the United States, Australia and Denmark, the focus is on the voluntary adoption of such workers and anti-discrimination legislation, while many others like France, Spain, and Germany, use a quota system to enforce the employment of disabled workers. This paper investigates whether the latter approach as legislated in Germany can promote the employment of disabled workers. In this type of legislation employers are required to fill a percentage of positions with severely disabled workers, or pay a fine in lieu of meeting the quota. More than onethird of countries in the OECD use a mandatory employment quota. For example, in Italy the quota is set at $7 \%$, while it is only $2 \%$ in Spain (OECD 2003). In Germany the quota currently stands at $5 \%$ as stipulated by the People with Severe Disabilities Act (PSDA) or Schwerbehindertengesetz, which is the main legislation that regulates the employment of workers with severe disabilities and applies to

both private and public employers. The PSDA covers persons who have difficulty 
in integrating into the labour force due to a non-temporary physical, intellectual, or psychological condition (Delsen 1996), and with the use of financial incentives, aims to integrate these individuals into the labour market.

However, the PSDA has not been particularly successful in reducing the unemployment of people with disabilities: in 1999, the unemployment rate for this group stood at $17.9 \%$ in comparison to $9.9 \%$ for the whole population. ${ }^{1}$ Furthermore, in 2001 the average unemployment duration was 13.4 months for the severely disabled, while it was only 8.5 months for the total population. ${ }^{2}$ Finally, the quota of $6 \%$ as set by the previous legislation (or the new quota of $5 \%$ ) has never been met, except in the public sector in recent years, which suggests that the PSDA has not provided the necessary incentives to reach this target. To address these problems, the Federal Government set a goal in September 2000 of reducing the number of unemployed people with severe disabilities by $25 \%$ before October 2002. As part of this campaign, the PSDA was reformed in January 2001, which involved an increase in the threshold for the applicability of the legislation for employers from 16 to 20 workers and a reduction in the quota for positions to be filled with disabled workers from $6 \%$ to $5 \%$. The levy charged for failure to comply with the quota was increased for larger employers with more than 59 employees and decreased for smaller establishments. Therefore, if the reform raised the incentives to hire disabled workers, it should have been the larger employers which reacted the most to the changes. The Government also initiated a widespread advertising campaign to raise the awareness of the reform amongst employers and people with disabilities. After the three year period had expired, it was announced that the reform was successful as the number of unemployed people with disabilities decreased by around 24\% (45,305 people) from October 1999 to October 2002 (Bundesministerium für Gesundheit und Soziale Sicherung 2003).

The main objective of this paper is to evaluate the impact of this reform on a range of labour market outcomes of people with severe disabilities using German individual data, the German Socio-Economic Panel (GSOEP). Since the reform

\footnotetext{
${ }^{1}$ Source: IAB Zahlen-Fibel 5.7.

${ }^{2}$ Source: Übersicht I/59, Amtlichen Nachrichten der Bundesanstalt für Arbeit, Strukturanalyse 2003.
} 
represented a change in the costs faced by firms, we would also ideally evaluate the effects of the reform on labour demand. However, the employment of people with disabilities is not identifiable in the available data sets, and thus, we are not able to directly estimate the effects of the legislative changes on employers. It is possible to investigate the impact on aggregate labour demand, though initial exploration of this has indicated that identification of any effects is very difficult. ${ }^{3}$

The employment effects of disability legislation have been explored by a number of previous studies. DeLeire (2000) and Acemoglu and Angrist (2001) find that the introduction of the Americans with Disability Act (ADA) in the United States in 1990 led to a reduction in employment rates for people with disabilities. The ADA requires employers to accommodate disabled workers and outlaws discrimination against the disabled in terms of hiring, firing and wages. The results indicate that the legislation imposed too many costs on potential employers and reduced their incentives to hire such workers. For Germany, Kölling, Schnabel, and Wagner (2001) consider the impact of the PSDA legislation on aggregate labour demand in small firms, though they do not estimate the impact of the 2001 reform, and moreover, were not able to investigate the demand for workers with severe disabilities. More recently, Lechner and Vazquez-Alvarez (2003) evaluate the treatment of becoming disabled on labour market outcomes in Germany. Using matching techniques and three year periods over 1984-2001, this study finds that those who become disabled experience lower employment rates and labour earnings relative to those who do not become disabled. This is not surprising since after the onset of the debilitating condition, many people are still in rehabilitation, and therefore, are not able to participate in the labour market. Moreover, the focus in this study is on the particular treatment of becoming disabled and they do not investigate the impact of the 2001 reform on these outcomes. Our paper contributes to this literature by estimating the effects of the PSDA reform on labour force participation.

The structure of the paper is as follows. The institutional setting, and in particular, the People with Severe Disabilities Act, is explained in Section 2. In Section 3 we present the econometric model and discuss identification issues. The data and

\footnotetext{
${ }^{3}$ This was done using the IAB Establishment Panel for the period 1998-2002. The size of the employer is not accurately defined in the GSOEP.
} 
descriptive statistics are reported in Section 4. In Section 5 the results are presented, and finally, we conclude in Section 6.

\section{Institutional Setting}

At the end of 2001 there were around 6.7 million people in Germany with a severe disability or $8.7 \%$ of the total population. ${ }^{4}$ In terms of the degree of disability, $25 \%$ were characterised as having a $100 \%$ disability, and $30 \%$ had a degree of $50 \%$ or more. The majority of the severely disabled were 55 years or older (75\%), with only around $23 \%$ between 18 and 55 years old. Given that the disabled were on average elderly, it is not surprising that the vast majority $(85 \%)$ became disabled through illness, while only around $2.5 \%$ acquired their condition through an accident or work-related illness. Thus, people with congenital disabilities are in the minority. Men were slightly more represented in the severely disabled (52\%). As a result of differences in definitions, surveys, cultural factors and the availability of disabilityrelated programs and benefits, the rate of disability in the population varies across countries. For example, using the OECD definition and data, almost $10 \%$ of the population aged 20-64 in Sweden are defined as being severely disabled compared to $5 \%$ for Germany. ${ }^{5}$

\subsection{The People with Severe Disabilities Act}

The People with Severe Disabilities Act (PSDA) or Schwerbehindertengesetz was enacted in 1974 to improve the integration of disabled workers into the labour market. In particular, the PSDA provides financial incentives for employers to hire disabled workers up to the quota and for people with disabilities to participate in the labour market by reducing entry costs. This legislation follows the guidelines of the World Health Organisation such that a severely disabled person is defined as someone who is limited in their capacity to integrate into the work force as a result of a physical, mental or psychological condition which is not temporary in nature (Delsen 1996).

\footnotetext{
${ }^{4}$ Source: see the Statisches Bundesamt, www.destatis.de.

${ }^{5}$ Figures are for 1999. Source: OECD (2003).
} 
The key points are that the definition is relative to the labour market and that the condition is permanent. The PSDA covers those with a degree of disability of $50 \%$ or more, though there are some provisions for individuals with between $30 \%$ and $50 \%$ disability if the authorities find that the disability restricts their ability in finding employment (Lechner and Vazquez-Alvarez 2003). The Versörgungsamt evaluates the individual's degree of disability. An example of a degree of $50 \%$ is a person with stunted growth such that their height is between 120 and $130 \mathrm{~cm}$. Another example of this level of disability is the loss of an arm from the elbow or a whole hand. On the basis of the medical evaluation, the Integrationsamt (earlier it was the Hauptfürsorgestelle) is then responsible for determining whether the individual is covered by the PSDA.

Similar to other legislation in Germany such as the Protection Against Dismissal Act or Kündigungsschutzgesetz, the coverage of the PSDA for employers is determined by a size threshold. Prior to January 2001, the PSDA applied only to employers with more than 15 workers, and according to figures from the Federal Ministry for Labor Services, in 2000 around 12\% of all firms in Germany were subject to the legislation. The quota for these employers was set at $6 \%$ of applicable positions, and when this level was not met, they were required to pay a levy of DM 200 per month for each vacant position. This implies that under the pre-2001 legislation, a firm with 16 workers needed to employ at least one disabled worker or pay DM 200 per month in fines for non-compliance. Part-time workers who work under 18 hours a week are not included in the calculation of the employer size for applicability of the PSDA, and those part-time workers who work 18 hours or more a week are calculated as contributing 0.5 of a worker to the number. ${ }^{6}$ Trainees are not included in this calculation. Workers who are deemed to be particularly difficult to hire and those who receive training within the firm are in certain cases counted as occupying 2-3 quota positions (O'Reilly 2003). Finally, workers with severe disabilities are given special employment protection in addition to the provisions of the Protection Against Dismissal Act. The PSDA requires that, if the employee has been working longer than 6 months, the employer needs permission for the dismissal from the

\footnotetext{
${ }^{6}$ The calculated firm size is rounded down to the nearest whole number for firms with up to 59 employees and rounded up for larger firms.
} 
local authority, the Integrationsamt. Contrary to the objective of this legislation, this stricter dismissal protection is likely to reduce the incentives for firms to hire people with severe disabilities, though employers could also hire such workers on a fixed-term contract.

In comparison to other legislation, the financial incentives stipulated in the PSDA are relatively clear for employers and if the costs of non-compliance are higher than the hiring costs for a disabled worker, they should find it optimal to employ such workers. There is also less uncertainty about the potential costs of the legislation as both the threshold value for the applicability of the PSDA and the fines for not fulfilling the quota are explicitly stated in the Act. For example, the provisions of the PSDA are simpler and less uncertain than those of the Protection Against Dismissal Act. Levies from non-complying employers are collected in a fund which are then used to facilitate and promote the employment of disabled workers, and to rehabilitate people after the onset of a disability. The funds are also used to support employers who meet or exceed their quota in the form of subsidies for the accommodation and training costs, and wages.

The quota of $6 \%$ as set by the previous legislation has never been achieved, though the public sector was usually close to fulfilling the required number of positions. For example, in 1995 only $4 \%$ of all jobs were filled by people with disabilities. This figure has remained relatively constant, falling marginally to $3.7 \%$ in $2000 .{ }^{7}$ As of October 1999, 143,773 (77\%) out of 187,437 employers subject to the PSDA did not meet the then quota of $6 \%{ }^{8}$ Furthermore, a large proportion of these $(71,199)$ did not employ any disabled workers. ${ }^{9}$ This suggests that penalties have been too low to provide strong incentives for employers to hire people with disabilities. This is supported by evidence reported in Georg and Stackelbeck (1997) who find that filling the quota played no role in influencing the decision to hire a worker with a dis-

\footnotetext{
${ }^{7}$ Source: IAB Zahlen-Fibel 5.6.

${ }^{8}$ For these figures and those reported below, refer to Bundesministerium für Gesundheit und Soziale Sicherung (2003).

${ }^{9}$ In 2001 around 30,893 employers actually had more disabled workers than the quota and these were mostly in the public sector, which on average comes much closer to meeting the required number of positions. After the reform in 2001, the public sector has largely fulfilled the quota of $5 \%$.
} 
ability, though larger firms come closer to meeting the number of required positions. As a result of the non-compliance, around DM 1.03 billion were collected in 2000 from employers who did not meet the quota and subsequently had to pay the levy of DM 200 per unfilled position. As discussed by Lechner and Vazquez-Alvarez (2003), there has been at the same time not enough people with disabilities registered as unemployed to satisfy the quota.

Given that employers seem to regard the levy as a tax and prefer these payments than to taking on disabled workers, it is not surprising that the PSDA has not been very successful in promoting the employment of people with disabilities. In 1999 the unemployment rate for people with disabilities stood at $17.9 \%$ in comparison to $9.9 \%$ for the whole population. ${ }^{10}$ As displayed in Figure 1, it is apparent from 1995 to 2001 that the unemployment rate for both the disabled and total population followed a very similar trend, with only a slight deviation in 1998. In the next section we address in more detail the reform of the PADA and how this affected the labour market outcomes for people with disabilities.

\subsection{Reform of the PSDA}

To address the persistence in the high rate of unemployment for people with disabilities, the Federal Government of Germany introduced in September 2000 some changes to the threshold and quota provisions in the PSDA. From January 2001, the threshold for the applicability of the legislation was increased from 16 to 20 and the quota for positions to be filled with disabled workers was reduced from $6 \%$ to $5 \%$. As announced by the Government, if the reform objective of a $25 \%$ reduction was not met by October 2002, the quota would be increased back to $6 \%$. With the increase in the threshold, the number of employers in Germany subject to the quota decreased from 187,437 in 1999 to 151,595 in 2001, a decrease of $19.1 \%$ (Bundesministerium für Gesundheit und Soziale Sicherung 2003). The levy charged for failure to comply with these measures was also adjusted to increase payments for larger employers while giving some relief to smaller ones. As displayed in Table 1, prior to January 2001 the levy stood at DM 200 per unfilled position per month.

\footnotetext{
${ }^{10}$ Source: IAB Zahlen-Fibel 5.7.
} 


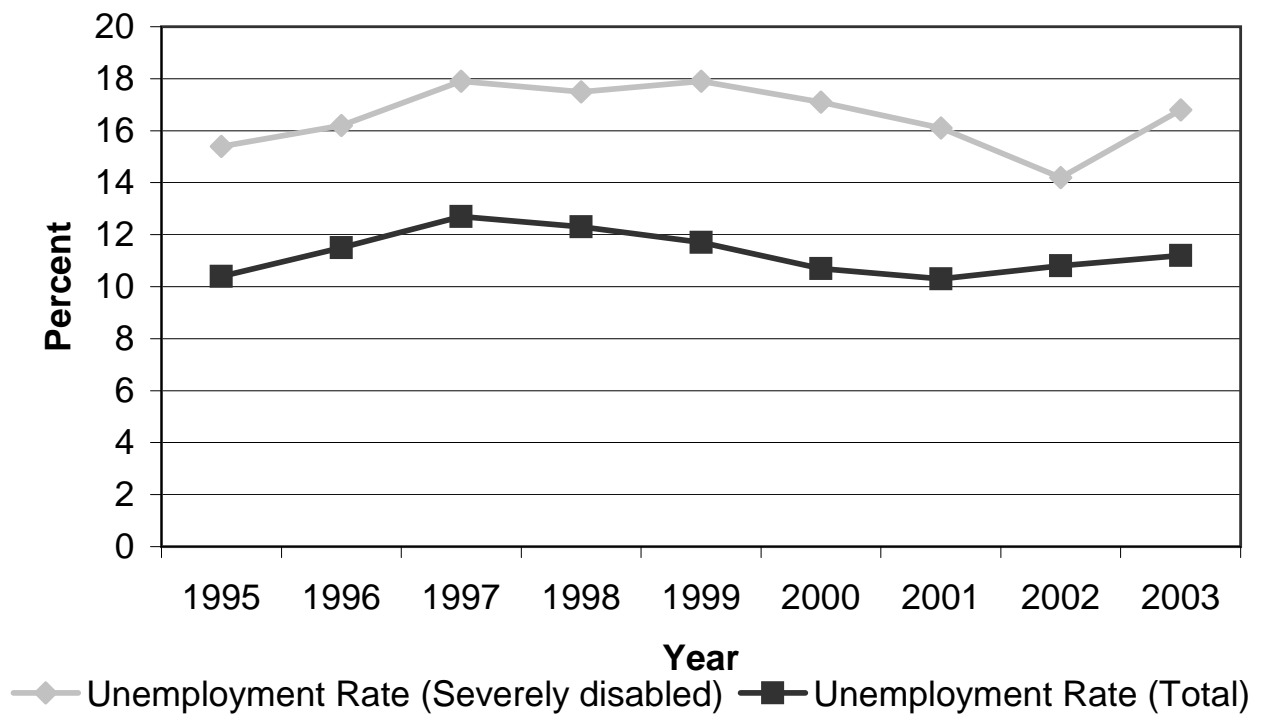

Figure 1: Unemployment Rate 1995-2003

Source: 1995-2001 - IAB Zahlen Fibel, 5.6. and 5.7. Figures for the Federal Republic of Germany. Unemployment rate is the unemployed as a \% of the dependent labour force; the disabled unemployed are for September of the reported year based on number of severely disabled people of working age in the previous year. 2002-2003 - See the Beauftragter der Bunderegierung für die Belange behinderter Menschen; 2002 rate is for October and the 2003 rate is for April.

After the reform, the schedule of penalties has become non-linear with respect to employer size. Employers with more than 59 employees have to now pay $€ 105$ per unfilled position per month if from 3 and up to $5 \%$ of positions are filled with severely disabled workers, $€ 180$ per unfilled position if from 2 and up to $3 \%$ are filled, and €260 per unfilled position if only less than $2 \%$ of positions are filled. Thus, the marginal cost of not employing a disabled worker is increasing with the number of unfilled positions, and therefore, should provide an incentive for large firms to at least fill one or two positions with a disabled worker. Under the new regulations, employers with between 20 and 39 employees are only required to have one disabled worker or pay $€ 105$ per month. Employers with between 40 and 59 employees are 
Table 1: Effects of the PSDA Reform on Employers by Size Class

\begin{tabular}{|c|c|c|c|}
\hline \multirow[t]{3}{*}{ Size $^{1}$} & \multicolumn{3}{|c|}{ Effects of 2001 Reform } \\
\hline & Requirements under & Requirements under & \\
\hline & old PSDA & new PSDA & Net effect \\
\hline $1-15$ & N.A. & N.A. & 0 \\
\hline $16-19$ & 1 worker or DM 200 levy & N.A. & + \\
\hline $20-39$ & 2 workers or DM 400 levy & 1 worker or DM 200 levy & + \\
\hline $40-59$ & 2-3 workers or DM 400/600 levy & 2 workers or DM 400 levy & + \\
\hline $60+$ & $3+$ workers or DM $600+$ levy & $3+$ workers or pay levy ${ }^{2}$ & - \\
\hline \multicolumn{4}{|c|}{1 Employer size as calculated according to the PSDA } \\
\hline \multicolumn{4}{|c|}{${ }^{2}$ Payment schedule is non-linear and depends on the degree the quota is not fulfilled } \\
\hline
\end{tabular}

required to pay $€ 105$ per unfilled position per month if they have only one disabled worker and $€ 180$ per unfilled position if they have none.

As listed in columns 2 and 3 of Table 1, different effects of the reform can be distinguished by firm size class. Firstly, there was no change for employers with 15 or less workers; they remain, as before, not subject to the PSDA. For employers with between 16 and 59 workers, the reform of 2001 represented a decrease in the costs imposed by the legislation in terms of the quota and the levy payments. However, the impact of the reform on the levy for non-compliance for the remaining employers, those with 60 or more workers, was negative. Thus, if the reform increased incentives for employers to hire people with disabilities, we expect that those with between 16 and 59 workers to employ less disabled workers, and those with 60 or more to employ more in the post-reform period. However, this assumes for the latter employers $(60+$ employees $)$ that the marginal productivity of the disabled worker, less the (subsidised) wage and accommodation costs, is higher than the penalty. If this is not the case, these employers would rather continue paying the levy as a tax than 
hiring such workers. It is also important to recognise that even though there was an increase in the levy payments for large employers, the costs as a percentage of total labour costs are still very small. For example, a firm with 100 employees is required under the current legislation to employ 5 disabled workers or pay $€ 1300$ per month or $€ 15,600$ per year in non-compliance levies. However, this amounts represents only $0.3 \%$ of total labour costs based on the average cost of a worker in 2000. ${ }^{11}$ According to figures from (Bundesministerium für Gesundheit und Soziale Sicherung 2003), the amount of non-compliance levies increased from DM 1.03 billion in 2000 to DM 1.149 billion in 2001. This indicates that the larger employers paid the higher fines instead of increasing the number of disabled workers. Therefore, though there were changes to the financial incentives for firms to hire disabled workers as a result of the PSDA reform, it was unlikely to have had a significant effect on the demand for such employees. In addition to these changes, the support for further education and subsidies for employers were also increased. Finally, the reform was highly publicised through an advertising campaign which targeted both employers and people with disabilities.

Turning to the impact of the 2001 reform on labour market outcomes, the number of unemployed people with severe disabilities decreased by around $24 \%$ from October 1999 to October 2002, representing approximately 45,305 individuals. In 2003 the Federal Government announced that its reform and campaign to reduce the unemployment of people with disabilities was a success, and subsequently, the quota remained at 5\% (until the end of 2003) (Bundesministerium für Gesundheit und Soziale Sicherung 2003). To see how this was achieved we first look at the changes in the aggregate data before turning to the individual data in Sections 4 and 5. As evident in Figure 1 and discussed above, the unemployment rate of people with disabilities for the period 1995-2000 has moved approximately in conjunction with that of the total population. There was a downwards trend in the unemployment rate for both the total population and the disabled from 1999 as economic conditions improved. However, the unemployment rate for the severely disabled continued to

\footnotetext{
${ }^{11}$ See Federal Statistical Office, www.destatis.de. This is consistent with figures quoted by OECD
} (2003). 
fall further in 2002 even though the unemployment rate for the population was increasing as the German economy deteriorated. This is preliminary evidence that the PSDA reform was successful in reducing the number of unemployed people with severe disabilities. However, the latest unemployment figures for the disabled are not very encouraging; as displayed in Figure 1, the unemployment rate for the disabled increased from 14.2\% in October 2002 to 16.8\% as of April 2003 (Bundesministerium für Gesundheit und Soziale Sicherung 2003). This suggests that the benefits of the reform were at best only temporary. The Federal Government argued that the main reason for this reversal was the weak German economy in 2003 (Bundesministerium für Gesundheit und Soziale Sicherung 2003). However, this does not explain why the number of unemployed fell in 2001 and 2002 when the economy was already stagnating. An alternative explanation could be that unemployed people with disabilities were given access to temporary training and employment support, after which they returned to unemployment benefits. Using individual data, the employment effects of the PSDA on labour force participation, and whether there is an explanation for the short-term benefits of the reform, are further investigated.

\section{Econometric Model and Identification}

As a consequence of the PSDA reform in 2001, we expect a number of effects on labour force participation. If the reform reduced entry costs for people with disabilities and if the changes to the levy system increased the demand for such workers in larger firms, employment rates for this group should have increased in the postreform period. To investigate this hypothesis, we evaluate the effects of the reform in 2001 on the employment, unemployment, and inactivity rates for people with disabilities. ${ }^{12}$ The important issue of incentives to enter early-retirement is discussed in Section 5.1. Due to the lack of appropriate data, we do not evaluate the effects on the demand for workers with severe disabilities.

Evaluation of the PSDA reform is based on a regression adjusted difference-in-

\footnotetext{
${ }^{12}$ The employment rate is equivalent to $\mathrm{E}-\mathrm{rate}=\mathrm{E} / \mathrm{E}+\mathrm{U}+\mathrm{I}$. The unemployment rate is based on the population participating in the labour market: $\mathrm{U}-\mathrm{rate}=\mathrm{U} / \mathrm{U}+\mathrm{E}$. Finally, the inactivity rate is based on the total population: $\mathrm{I}-\mathrm{rate}=\mathrm{I} / \mathrm{E}+\mathrm{U}+\mathrm{I}$.
} 
differences estimator, which uses the pre- and post-reform periods to compare the outcomes for the severely disabled (treatment group) in comparison to the nonand moderately-disabled (control group). As the reform was largely unexpected, selection into the treatment state should not be a problem. Moreover, selection based on time-invariant differences between the treatment and control groups are differenced out in this methodology. We use three calendar years prior to the reform (1998-2000) and three years after the reform in January 2001 (2001-2003). This allows us to identify heterogeneous effects of the reform in the post-reform period. It is also possible to check whether there is any evidence of pre-reform effects on the outcome variables, which would be an indication that the changes were part of an earlier trend. To identify these effects we use the following econometric specification

$$
Y_{i t}=\alpha+\gamma^{\prime} X_{i t}+\beta d_{i}+\sum_{k=1999}^{2003} \tau_{k} \lambda_{k}+\sum_{k=1999}^{2003} \delta_{k}\left(\lambda_{k} \cdot d_{i}\right)+\epsilon_{i t},
$$

where $Y_{i t}$ is the labour market outcome variable for individual $i$ in period $t$. The main outcome variables investigated in this paper are the rates of employment, unemployment, inactivity, and the rates of transition out of unemployment into employment and inactivity. $X_{i t}$ is a vector of control variables including a sex dummy, age, age-squared, years of education, a dummy for being married, dummies for different high school degrees, a dummy whether the individual is satisfied with their health, a dummy for living outside a major city, and a dummy for being in East Germany. For a full description of the control variables, see Table 8 in the Appendix. These variables control for observed differences between the people with severe disabilities and those without, and which are likely to influence labour market outcomes. For example, it is clear from the descriptive statistics in Table 2, that the severely disabled are on average older and this may result in lower labour force participation rates regardless of the disability. The binary variable $d_{i}$ is equal to one if individual $i$ is severely disabled and zero otherwise and controls for timeinvariant differences between the two groups. ${ }^{13} \lambda_{k}$ is a vector of year dummies which captures time effects that are constant across groups, where the base year is 1998. In terms of evaluating the reform, the primary interest is in the estimates

\footnotetext{
${ }^{13} \mathrm{We}$ are only comparing individuals who are either permanently disabled or non-disabled.
} 
of the coefficients on the product of the dummy for being severely disabled $d_{i}$ and the year dummies $\lambda_{k}$. The vector of coefficients $\delta_{k}$ identifies the relative impact of the reform on the labour market outcomes for people with severe disabilities in comparison to the base year 1998. With this specification, we are able to isolate the changes to the outcome variables after 2001. $\epsilon_{i t}$ is a random error term and is likely to be correlated within group-year cells. Ignoring this serial correlation can bias the estimated standard errors downwards, which would increase the probability of rejecting the null hypothesis that there is no significant effect of the reform.

The main identification assumption of equation (1) is that the error term is not correlated with the product of the dummies dummy $\left(\lambda_{k} \cdot d_{i}\right)$ such that $E\left(\epsilon_{i t} \mid\left(\lambda_{k}\right.\right.$. $\left.\left.d_{i}\right)\right)=0$. This implies that coefficients $\delta_{k}$ would be zero in the absence of the reform to the PSDA in 2001. Furthermore, the specification of equation (1) assumes that the vector of coefficients $\beta$ is equal across both the treatment and control groups. Moreover, since we only include common year dummies, we assume that any macroeconomic trends affect both the severely disabled and control group equally. This can be a particular threat to the validity of this estimator. For example, there may have been macroeconomic shocks or other changes in legislation such early retirement schemes that affected the severely disabled and non-disabled differently.

\section{Data and Descriptive Statistics}

For the empirical evaluation of the impact of the PSDA reform on labour force participation amongst people with severe disabilities, we use the German SocioEconomic Panel (GSOEP), an individual panel data set which is well suited to looking at the severely disabled.

The GSOEP is a representative longitudinal study of private households and provides information on all household members, consisting of Germans living in West and East Germany, foreigners, and recent immigrants. The GSOEP was started in 1984, and in 2000, there were more than 12,000 households, representing over 20,000 individuals. The topics in the survey include household composition, occupational biographies, employment, earnings, health and satisfaction indicators. In the health 
section, individuals are asked firstly if they are "legally classified as handicapped or capable of gainful employment only to a reduced extent due to medical reasons". Secondly, these individuals are then asked to what "extent is this capability reduction or handicap according to the most recent diagnosis". ${ }^{14}$ Therefore, it is possible to identify whether a person is legally disabled and the degree of their disability, which is important in terms of the legislation coverage.

For estimating equation (1), we restrict the sample to those of working age (25-55) since we wish to isolate the employment effects of the legislation from the incentives to take up (early) retirement benefits. We discuss and investigate this important assumption in Section 5.1. We also drop people with a disability of $90 \%$ or more as they are unlikely to be able to participate in the mainstream labour market and would therefore not have been affected by the reform. In our selected sub-sample, $2.95 \%$ (1,874 person-year observation) are severely disabled with a degree of disability of $50 \%$ or more. This figure is lower than in the population as we have excluded the elderly who make up the majority of the disabled. Of the people with severe disabilities, there are number of individuals who became disabled during the period 1998-2003, or who are only disabled for one or two years. To avoid compounding effects from rehabilitation and other measures that are provided to individuals after the onset of the disability, we include only those who are permanently disabled for the whole 6 years. This restriction is in contrast to Lechner and Vazquez-Alvarez (2003) who focus on the treatment of becoming disabled. However, when looking at this process, it is not surprisingly that employment rates and incomes are lower after the onset of the disability. In particular, this is likely to be the consequence of people entering rehabilitation after becoming disabled. In such an intensive program, it is expected that these individuals are not able to participate in the labour market, and hence, do not earn the same income. In contrast, the focus in this paper is on whether the reform of the PSDA had an effect on the employment of people with permanent disabilities. This leaves us with 1,237 person-year observations for people with severe disabilities or $1.99 \%$ of the total sub-sample $(62,128$ observations). Secondly, Lechner and Vazquez-Alvarez (2003) include people with

\footnotetext{
${ }^{14}$ See Table 8 in the Appendix for more details about these variables.
} 
Table 2: Descriptive Statistics

\begin{tabular}{|c|c|c|c|}
\hline & Non-Disabled & Dis & bled \\
\hline & & Severe & Moderate \\
\hline Variable & Mean & Mean & Mean \\
\hline Demographics & & & \\
\hline Male (\%) & 50.1 & 50.4 & 59.8 \\
\hline Age & 39.6 & 45.4 & 45.3 \\
\hline Married (\%) & 68.3 & 61.9 & 72.5 \\
\hline Years of education & 12.2 & 11.5 & 11.8 \\
\hline Labour market outcomes & & & \\
\hline Employment rate (\%) & 83.4 & 51.7 & 78.1 \\
\hline Full-time rate(\%) & 64.6 & 40.2 & 64.8 \\
\hline Part-time rate $(\%)$ & 14.4 & 7.0 & 10.7 \\
\hline Marginal work rate $(\%)$ & 3.8 & 2.9 & 1.8 \\
\hline Hours per week & 39.2 & 37.9 & 41.1 \\
\hline Unemployment rate (\%) & 6.9 & 17.1 & 9.9 \\
\hline Inactivity rate $(\%)$ & 10.4 & 37.8 & 13.3 \\
\hline Income $(€)$ & 23,589 & 13,460 & 24,720 \\
\hline & $(20,432)$ & $(16,359)$ & $(22,054)$ \\
\hline & {$[22,000]$} & {$[4,500]$} & {$[23,048]$} \\
\hline Non-zero income $(€)$ & 26,765 & 22,966 & 29,641 \\
\hline & $(19,715)$ & $(15,436)$ & $(20,910)$ \\
\hline & {$[24,500]$} & {$[21,850]$} & {$[27,508]$} \\
\hline Household income $(€)$ & 44,009 & 28,019 & 45,383 \\
\hline & $(28,292)$ & $(24,615)$ & $(30,506)$ \\
\hline & {$[39,881]$} & {$[24,998]$} & {$[40,020]$} \\
\hline Tenure (years) & 9.0 & 11.8 & 13.4 \\
\hline No of Obs. & 59,065 & 1237 & 512 \\
\hline
\end{tabular}

Source: GSOEP - 1998-2003, Samples A-F. Standard deviations are reported in parentheses and medians are reported in the square brackets. Employment rate $=(\mathrm{E} / \mathrm{E}+\mathrm{U}+\mathrm{IA}) * 100$, Unemployment rate $=(\mathrm{U} / \mathrm{U}+\mathrm{E}) * 100$, Inactivity rate $=$ $(\mathrm{IA} / \mathrm{E}+\mathrm{U}+\mathrm{IA}) * 100$. Severely disabled $=50+\%$ degree of disability. Moderately disabled $=30-49 \%$ degree of disability. 
a degree of disability of between 30 and $49 \%$ in the treatment group since the legislation is applicable to these individuals in certain cases. We check in both the descriptive statistics and the results below whether this is a reasonable assumption. In our sub-sample, there are 512 observations for people with this degree of disability and who are permanently disabled during 1998-2003. To keep the distinction clear, we label those with a degree of disability of $50 \%$ or more as severely disabled and those with a degree of 30-49\% as moderately disabled. Individuals with a degree of less than $30 \%$ are included in the non-disabled group. Though these mildly disabled only represent 374 observations, the sensitivity of the results regarding their allocation to the control group, in addition to other assumptions, is further discussed in Section 5.

In Table 2 the descriptive statistics for the variables are displayed separately for the non-disabled and those with severe and moderate disabilities, which are defined as above. We start by comparing the labour market characteristics for people with severe disabilities and the non-disabled. In general, the differences between the two groups are in line with the population statistics discussed above in Section 2. Firstly, the employment rate of the non-disabled is on average much higher, at $83.4 \%$ compared to $51.7 \%$ for the severely disabled. This difference is largely driven by the much lower number of people with disabilities in full-time employment. The disabled work 37.9 hours per week compared to 39.2 hours per week for the non-disabled. Secondly, consistent with Figure 1, the unemployment rate is more than twice as high for the severely disabled: $17.1 \%$ compared to $6.9 \%$. Thirdly, the participation rate of people with severe disabilities is significantly lower with around $37.8 \%$ not actively participating in the labour market, compared to only $10.4 \%$ for the non-disabled. This confirms that it is not only the higher unemployment rates but also the lower participation rates that drives the low employment rates of the severely disabled. In terms of wages, people with severe disabilities earn on average less, $€ 13,460$ versus $€ 23,589$, which is even greater when looking at the median, $€ 4,500$ compared to $€ 22,000$. The earnings of a household where a person with a disability is resident are also lower on average. However, this earnings differential is largely generated by zero reported wage income, and when taking only the non-zero observations, 
the average income for a disabled person increases to $€ 22,966$, while it is $€ 26,765$ for the non-disabled. ${ }^{15}$ This is consistent with OECD (2003) which illustrates that when comparing working individuals, there is less of a difference in the non-zero labour incomes of the disabled and non-disabled, and the gap in incomes results from the lower employment rates of people with disabilities. Unionisation and antidiscrimination legislation make it difficult for employers to pay lower wages to people with severe disabilities than their non-disabled equivalents.

Turning to the socio-demographic characteristics, people with severe disabilities tend to be on average around 6 years older than the non-disabled. There is no significant difference between the proportion of males, while the percentage married is higher for the non-disabled. In the sample, people with severe disabilities have on average slightly fewer years of education. The disabled are also more likely $(46.3 \%$ versus $29.2 \%$ ) to have completed a Hauptschulabschluss or Lower Secondary School Certificate, which only requires 9 years of schooling and is usually followed by a part-time course at a vocational college and an apprenticeship. People without disabilities are also more likely to have been at a Realschule or Middle Secondary School, $36.2 \%$ versus $28.3 \%$, which consists of 10 years and is followed by vocational school of a more advanced level than after a Hauptschulabschluss. As a result, fewer people with severe disabilities have an Arbiturabschluss or Higher Secondary School Certificate: $10.4 \%$ compared to $18.7 \%$. The Arbitur usually leads on to university education, and it is therefore not surprising that the people with severe disabilities are less likely to have a tertiary degree.

In comparing these demographic characteristics, it must be remembered that these outcomes are not necessarily the result of the disability since the majority of this group would have acquired their condition. It is, however, possible that selection is important in the sense that becoming disabled is not random and that certain observed characteristics such as education are correlated with the probability of being injured or becoming ill. The figures presented by OECD (2003) show that disability prevalence rates are indeed significantly higher among individuals with lower levels of education.

\footnotetext{
${ }^{15}$ However, using a one-sided t-test, this gap remains statistically significant. The t-value of the difference is 6.555 with 756 degrees of freedom.
} 
In contrast, people with moderate disabilities, those with a degree of disability between 30 and 49\%, are more likely to be male and married than both the nondisabled and severely disabled. The employment rate of the moderately disabled $(78.1 \%)$ is closer to that of the non-disabled. Moreover, the unemployment rate $(9.9 \%)$ is more similar to that of the non-disabled $(6.9 \%)$ and considerably lower than the rate for the severely disabled (17.1\%). Interestingly, the wage incomes are higher than for the non-disabled. It is likely that the moderately disabled are individuals who became disabled during employment and continued in the same job after the onset of the disability. The longer average tenure (13.4 years) is consistent with this hypothesis. From the descriptive statistics in Table 2, it is clear that people with disabilities are not a homogeneous group, and in particular, there are some significant differences in the labour market outcomes for the moderately and severely disabled.

It is also useful to compare how the labour market outcomes for people with disabilities and the non-disabled vary over the period 1998-2003. As mentioned in Section 2, the unemployment rate for the severely disabled came down from $17.9 \%$ in October 1999 to $14.2 \%$ in October 2002, before increasing again to $16.8 \%$ in April 2003. The individual data in the GSOEP indicates a similar trend and as illustrated in Figure 2, the unemployment rate for the severely disabled decreased from $22.7 \%$ in 1998 to $10.5 \%$ in 2003 . The rate is decreasing over the whole period, converging towards the unemployment rate of the non-disabled. However, the fastest decline occurs in the two years after the reform (2002-2003), though there is no indication of the increase in unemployment of the severely disabled in 2003 as suggested by the macro data (see Figure 1). In comparison, the unemployment rate for the non-disabled fell from $8.0 \%$ in 1998 to $6.1 \%$ in 2001. After this low point, the rate increased to $6.8 \%$ in 2002, and then further to $8.3 \%$ in 2003 as economic conditions in Germany deteriorated. The average unemployment rate for the moderately disabled fluctuates over the 5 years. Although there is some evidence that unemployment of this group decreased slightly from 2001 to 2003, it is not to the same extent as experienced by the severely disabled.

As displayed in Figure 3, the employment rate for both the severely disabled and 


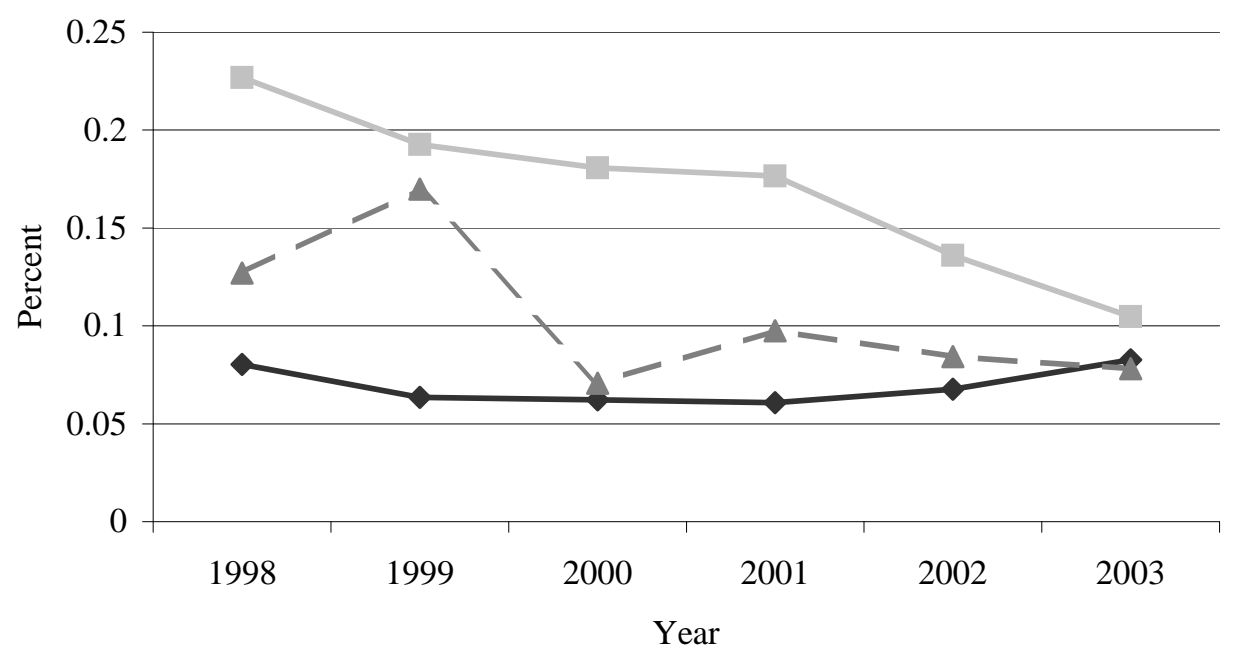

$\longrightarrow$ Non-disabled $\longrightarrow$ Sev. Disabled $\longrightarrow \Delta \longrightarrow$ Mod. Disabled

Figure 2: Unemployment Rate - GSOEP 1998-2003

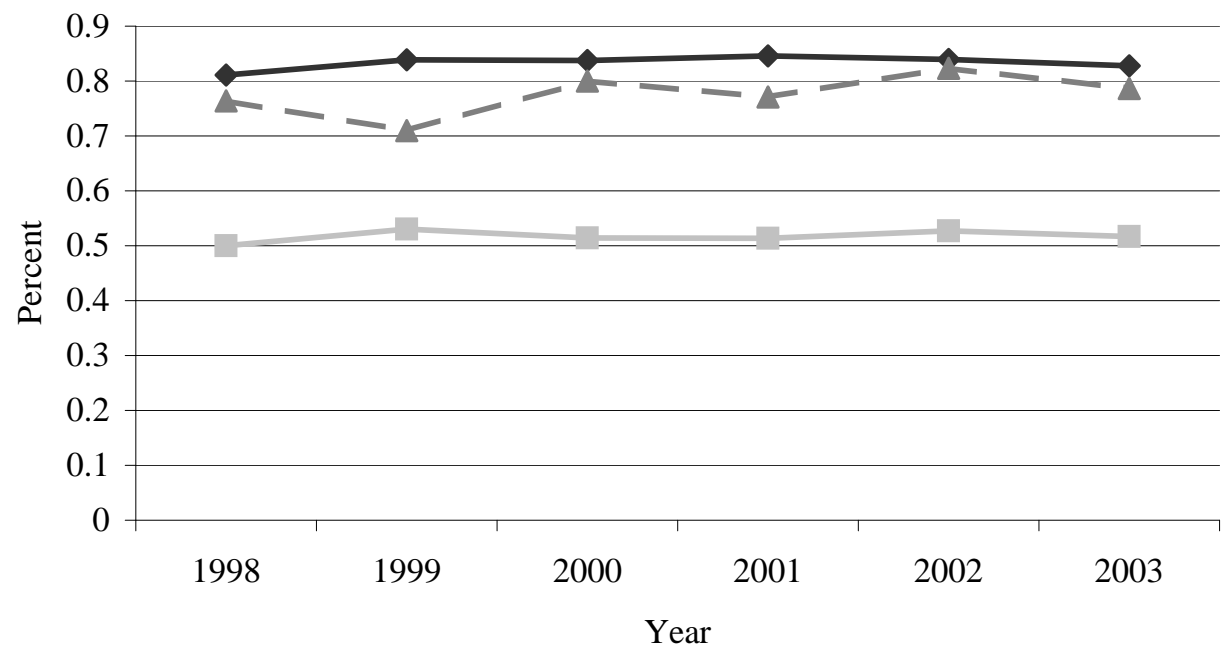

$\longrightarrow$ Non-disabled $\longrightarrow-$ Sev. Disabled $\longrightarrow \triangle-$ Mod. Disabled

Figure 3: Employment Rate - GSOEP 1998-2003 


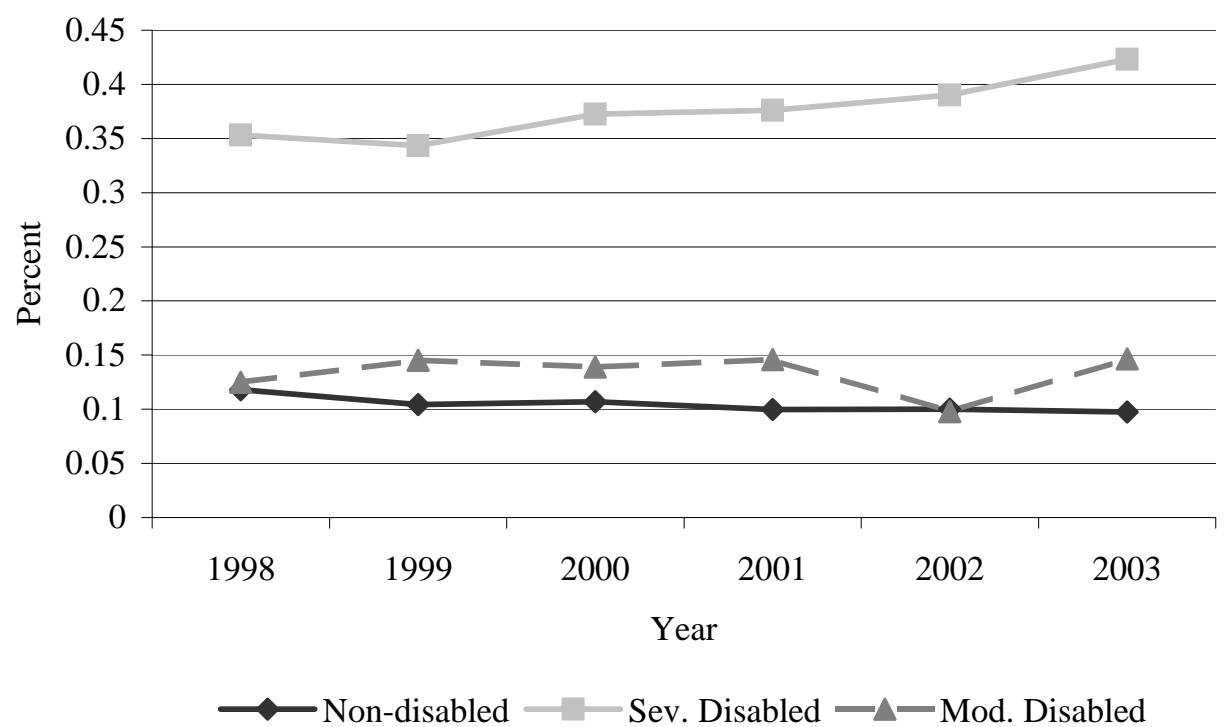

Figure 4: Inactivity Rate - GSOEP 1998-2003

non-disabled have remained relatively constant. The trend in the employment rate for people with moderate disabilities is similar, but there was a small decrease in the average rate in 1999, which is consistent with the increase in the unemployment rate for this group in that year. Moreover, as illustrated in Figure 4, the inactivity rate has increased for the severely disabled from 1998 to 2003 with the largest change occurring in 2003. In comparison, the non-participation rate for the non-disabled was relatively constant. The rate for the moderately disabled increased in the first 4 years before decreasing in 2002. In 2003 there was again an increase in the nonparticipation rate for this latter group, suggesting that the 2002 achievement was temporary. In general, this preliminary evidence implies that the reduction in the number unemployed people with severe disabilities was achieved by these individuals exiting the labour force, rather than entering paid employment.

The effect of the PSDA reform on the labour market participation of people with disabilities can also be investigated by comparing the inflows and outflows from employment, unemployment, or inactivity. The mean of the raw transition rates for the non-disabled and severely disabled are listed in Table 3. The rows 
Table 3: Raw Transition Rates

\begin{tabular}{|c|c|c|c|}
\hline \multicolumn{4}{|c|}{ A. Non-disabled } \\
\hline & Employed $_{t+1}$ & Unemployed $_{t+1}$ & Inactivity $_{t+1}$ \\
\hline \multirow[t]{2}{*}{ Employed $_{t}$} & 0.951 & 0.029 & 0.020 \\
\hline & $(33,913)$ & $(1028)$ & $(719)$ \\
\hline \multirow[t]{2}{*}{ Unemployed $_{t}$} & 0.374 & 0.516 & 0.109 \\
\hline & $(900)$ & $(1241)$ & $(263)$ \\
\hline \multirow[t]{2}{*}{ Inactivity $_{t}$} & 0.243 & 0.050 & 0.707 \\
\hline & $(1019)$ & $(211)$ & $(2972)$ \\
\hline \multicolumn{4}{|c|}{ B. Severely disabled } \\
\hline & Employed $_{t+1}$ & Unemployed $_{t+1}$ & Inactivity $_{t+1}$ \\
\hline \multirow[t]{2}{*}{ Employed $_{t}$} & 0.903 & 0.042 & 0.055 \\
\hline & $(411)$ & $(19)$ & $(25)$ \\
\hline \multirow[t]{2}{*}{ Unemployed $_{t}$} & 0.215 & 0.559 & 0.226 \\
\hline & $(20)$ & $(52)$ & $(21)$ \\
\hline \multirow[t]{2}{*}{ Inactivity $_{t}$} & 0.053 & 0.043 & 0.905 \\
\hline & $(16)$ & $(13)$ & $(275)$ \\
\hline
\end{tabular}

Source: GSOEP - 1998-2003, Samples A-F. The severely disabled consists of people with a degree of disability of $50-89 \%$ who are permanently disabled. The number of observations in the respective cell are reported in parentheses.

denote three labour market outcomes in period $t$ : employed; unemployed; and inactivity. The columns denote the same outcomes but in period $t+1$, such that the first cell represents the rate of remaining in employment from period $t$ to $t+1$. From these figures, it is evident that the state of being employed is absorbing for both the severely disabled and non-disabled, though the outflows from employment to unemployment and inactivity are approximately twice as high for people with severe disabilities. Moreover, the transitions from unemployment to employment is much lower for the severely disabled, and the outflow from unemployment to inactivity is 
higher for this group. Together with the descriptive statistics discussed above, this suggests that rather than finding employment, people with disabilities for reasons of health, lack of motivation or due to financial incentives, drop all together out of the labour market. Furthermore, as clear in the last row of the table, once inactive the severely disabled have a much lower rate of rejoining the labour force in comparison to the non-disabled.

\section{Results}

To evaluate the effects of the PSDA reform on labour market outcomes, we estimate equation (1) as a linear probability model. The outcome variables, employment, unemployment, and inactivity rates, in addition to the transition rates from these three labour market states, are all binary. To control for observed differences between the severely disabled and the non-disabled, we include as right-hand side variables a gender dummy, age, age-squared, years of education, a dummy for being married, dummies for different high school degrees, a dummy whether the individual is satisfied with their health, a dummy for living outside a major city, and a dummy for being in East Germany.

The results for the employment rate specification are displayed in column 1 of Table 4 and indicate as expected, that being severely disabled reduces the probability of being employed by 0.25 . However, the coefficients on the interaction terms are all insignificant, and thus, there is no indication that the reform increased the employment of the severely disabled. The coefficients on the year dummies do, however, reveal a general upwards trend in the probability of being employed. All other variables are significant in this specification. The gender coefficient indicates that men are more likely to be employed, while those who are married have a lower probability of being employed. As expected, the probability of employment increases with age (at a marginally decreasing rate) and years of education. Surprisingly, individuals with a Higher Secondary School degree (Arbitur) and those with a Lower Secondary School degree (Hauptschule) have a lower, respectively, higher probability of employment as compared to those with a Middle Secondary School degree 
Table 4: Impact of the Reform to the PSDA on the Probability of Labour Market Outcomes

\begin{tabular}{|c|c|c|c|}
\hline \multirow[b]{2}{*}{ Variables } & \multicolumn{3}{|c|}{ Dependent variable } \\
\hline & $\begin{array}{c}(1) \\
\text { Employment }\end{array}$ & $\begin{array}{c}(2) \\
\text { Unemployment }\end{array}$ & $\begin{array}{c}(3) \\
\text { Inactivity }\end{array}$ \\
\hline Disabled & $\begin{array}{c}-0.254^{* * *} \\
(0.037)\end{array}$ & $\begin{array}{c}0.116^{* * *} \\
(0.038)\end{array}$ & $\begin{array}{c}0.210^{* * *} \\
(0.035)\end{array}$ \\
\hline Disabled*1999 & $\begin{array}{c}0.016 \\
(0.032)\end{array}$ & $\begin{array}{l}-0.026 \\
(0.039)\end{array}$ & $\begin{array}{c}0.001 \\
(0.030)\end{array}$ \\
\hline Disabled $* 2000$ & $\begin{array}{l}-0.005 \\
(0.036)\end{array}$ & $\begin{array}{l}-0.023 \\
(0.040)\end{array}$ & $\begin{array}{c}0.027 \\
(0.035)\end{array}$ \\
\hline Disabled*2001 & $\begin{array}{l}-0.022 \\
(0.041)\end{array}$ & $\begin{array}{l}-0.034 \\
(0.041)\end{array}$ & $\begin{array}{c}0.048 \\
(0.039)\end{array}$ \\
\hline Disabled*2002 & $\begin{array}{c}0.003 \\
(0.042)\end{array}$ & $\begin{array}{l}-0.077^{*} \\
(0.045)\end{array}$ & $\begin{array}{c}0.058 \\
(0.040)\end{array}$ \\
\hline Disabled ${ }^{*} 2003$ & $\begin{array}{l}-0.003 \\
(0.044)\end{array}$ & $\begin{array}{c}-0.121^{* * *} \\
(0.044)\end{array}$ & $\begin{array}{c}0.095^{* *} \\
(0.043)\end{array}$ \\
\hline 1999 & $\begin{array}{c}0.025^{* * *} \\
(0.004)\end{array}$ & $\begin{array}{c}-0.015^{* * * *} \\
(0.004)\end{array}$ & $\begin{array}{c}-0.012^{* * *} \\
(0.003)\end{array}$ \\
\hline 2000 & $\begin{array}{c}0.015^{* * * *} \\
(0.004)\end{array}$ & $\begin{array}{c}-0.010^{* * *} \\
(0.004)\end{array}$ & $\begin{array}{l}-0.005 \\
(0.004)\end{array}$ \\
\hline 2001 & $\begin{array}{c}0.021^{* * *} \\
(0.005)\end{array}$ & $\begin{array}{c}-0.011^{* * *} \\
(0.004)\end{array}$ & $\begin{array}{c}-0.011^{* * * *} \\
(0.004)\end{array}$ \\
\hline 2002 & $\begin{array}{c}0.013^{* * * *} \\
(0.005)\end{array}$ & $\begin{array}{l}-0.004 \\
(0.004)\end{array}$ & $\begin{array}{c}-0.010^{* *} \\
(0.004)\end{array}$ \\
\hline 2003 & $\begin{array}{c}0.002 \\
(0.005)\end{array}$ & $\begin{array}{c}-0.010 \\
(0.004)\end{array}$ & $\begin{array}{c}-0.012^{* * *} \\
(0.004)\end{array}$ \\
\hline Sex & $\begin{array}{c}0.155^{* * *} \\
(0.005)\end{array}$ & $\begin{array}{c}-0.013^{* * * *} \\
(0.003)\end{array}$ & $\begin{array}{c}-0.154^{* * *} \\
(0.004)\end{array}$ \\
\hline Age & $\begin{array}{c}0.013^{* * *} \\
(0.003)\end{array}$ & $\begin{array}{c}-3.52 \mathrm{e}-04 \\
(0.002)\end{array}$ & $\begin{array}{c}-0.014^{* * *} \\
(0.002)\end{array}$ \\
\hline Age2 & $\begin{array}{c}-1.55 \mathrm{e}-04^{* * *} \\
(3.53 \mathrm{e}-05)\end{array}$ & $\begin{array}{c}5.61 \mathrm{e}-06 \\
(2.42 \mathrm{e}-05)\end{array}$ & $\begin{array}{c}1.70 \mathrm{e}-04^{* * *} \\
(2.94 \mathrm{e}-05)\end{array}$ \\
\hline Yrsedu & $\begin{array}{c}0.033^{* * *} \\
(0.002)\end{array}$ & $\begin{array}{c}-0.017^{* * *} \\
(0.002)\end{array}$ & $\begin{array}{c}-0.020 * * * \\
(0.002)\end{array}$ \\
\hline Married & $\begin{array}{c}-0.011^{*} \\
(0.006)\end{array}$ & $\begin{array}{c}-0.042^{* * *} \\
(0.005)\end{array}$ & $\begin{array}{c}0.054^{* * *} \\
(0.004)\end{array}$ \\
\hline Arbitur & $\begin{array}{c}-0.055^{* * *} \\
(0.011)\end{array}$ & $\begin{array}{l}0.009 \\
(0.007)\end{array}$ & $\begin{array}{c}0.056^{* * *} \\
(0.010)\end{array}$ \\
\hline
\end{tabular}


Table 4: (continued)

\begin{tabular}{l|c|c|c}
\hline \hline Haupt & $0.061^{* * *}$ & $-0.035^{* * *}$ & $-0.033^{* * *}$ \\
& $(0.006)$ & $(0.004)$ & $(0.005)$ \\
University & $-0.024^{* *}$ & $0.017^{* *}$ & $0.015^{*}$ \\
& $(0.010)$ & $(0.007)$ & $(0.008)$ \\
Health & $0.117^{* * *}$ & $-0.082^{* * *}$ & $-0.055^{* * *}$ \\
& $(0.009)$ & $(0.008)$ & $(0.008)$ \\
Non-city & $0.032^{* *}$ & $-0.043^{* * *}$ & 0.006 \\
& $(0.014)$ & $(0.010)$ & $(0.011)$ \\
East & $-0.055^{* * *}$ & $0.108^{* * *}$ & $-0.049^{* * *}$ \\
& $(0.006)$ & $(0.005)$ & $(0.004)$ \\
\hline No of Obs. & 60,744 & 54,179 & 60,744 \\
\hline \hline
\end{tabular}

\begin{abstract}
Source: GSOEP - 1998-2003, Samples A-F. The severely disabled consists of people with degree of disability of $50-89 \%$ who are permanently disabled. For the unemployment rate, the sample only includes individuals who participate in the labour market by either being employed or unemployed. All specifications are estimated as a linear probability model. Standard errors corrected for heteroskedasticity and clustering are reported in the parentheses. ${ }^{* * *}$ - $1 \%$ significance level, $* *$ - $5 \%$ significance level, $*$ - $10 \%$ significance level.
\end{abstract}

(Realschule). Thus, individuals who go to a Hauptschule, which is typically followed by an apprenticeship, are more likely to be employed than those who prepare for a tertiary education (Arbitur) or that of the Realschule. The negative sign of the coefficient on the dummy for having a tertiary degree supports this claim. Individuals who are satisfied with their health have a higher probability of employment, though the casuality could go in the other direction. The regional variables indicate that probability of employment increases for people outside major cities and in West Germany.

The coefficient estimates for the specification for the unemployment rate are reported in column (2) of Table 4. Consistent with the discussion in Sections 1 and 2 , the probability of being unemployed is on average 12\%-points higher for the severely disabled than those in the control group. The coefficients on the interacted terms indicate that the probability of unemployment already started decreasing 
in 1999. However, only the coefficients on the interaction terms for the last two years are significant, and imply that there was a decline in the probability of being unemployed for the severely disabled in both 2002 (-0.077) and 2003 (-0.121). Thus, the convergence of the unemployment rates for people with severe disabilities with that of the total (or non-disabled) population remains evident even after controlling for a range of individual characteristics. If we can interpret these effects as causal, this is evidence that, though the unemployment rate was falling from 1999, the reform to the PSDA in 2001 reduced the rate further and to a greater extent. As also noted in Section 4, the estimates do not indicate an increase in the unemployment rate for the severely disabled in 2003. The coefficients on the year dummies are negative and significant for 1999-2001, and reflect that the unemployment rates for both groups had a downward trend over this period. The unemployment rate then stopped falling as the economy stagnated in 2002 and 2003. The coefficients on the other variables imply that men have a lower probability of being unemployed, but surprisingly age is not correlated with this state. Years of education, marriage, having a Lower Secondary School degree (Hauptschule), satisfaction with health, and those living outside a major city are negatively and significantly correlated with the probability of being unemployed. Given the economic conditions in East Germany, it is not surprising that individuals in this region are more likely to be unemployed.

Turning to the last state of inactivity, we see in column (3) of Table 4 that the severely disabled are more likely to be inactive, which is not surprisingly given the uptake of disability benefits and problems associated with labour force participation for this group. The coefficients on the interaction terms for 1999-2003 are all positive but only the coefficient for 2003 is significant. The aim of the PSDA reform in 2001 was not to increase the non-participation rate, though it is possible that the positive increase in the 2nd year after the reform is due to other factors such as changes to the incentives for early retirement. However, we have restricted the sample to the working population, and therefore, it is more likely that such individuals exited the labour market and subsequently received a disability pension. The coefficients on the year dummies imply that there was a decrease in the probability of being inactive 
from 1999 to 2003 for the whole sample. Most of the coefficients on the demographic variables are similar to that in the specification for the probability of unemployment, though the coefficients on age (negative), age-squared (positive) and having a Higher Secondary School degree (positive) are now significant. In contrast to the results for unemployment, individuals in East Germany have a lower probability of being inactive.

We can also compare the above results to the standard difference-in-differences (DID) estimator which identifies the average effect of the reform on the labour market outcomes for the severely disabled by comparing the means for this group to the means for non-disabled outcomes. The DID estimator can be stated as: $\delta=\left(\bar{Y}_{t_{1}}^{1}-\bar{Y}_{t_{0}}^{1}\right)-\left(\bar{Y}_{t_{1}}^{0}-\bar{Y}_{t_{0}}^{0}\right)$, where $\bar{Y}_{t}^{1}$ is the mean outcome for the severe disabled in period $t$, and likewise, $\bar{Y}_{t}^{0}$ is the mean outcome for the control group in period $t$. The means are averaged over the pre-reform period $\left(t_{0}=1998-2000\right)$ and the post-reform period $\left(t_{1}=2001-2003\right)$. The estimates using this approach are entirely consistent with those reported in Table 4. Firstly, the effect of the reform on employment of people with severely disabled is insignificant. Secondly, the average effect of the reform on the unemployment rate for the disabled decreases to -0.083 (and remains significant) in comparison to -0.121 as reported in Table 4. Finally, the average effect in the case of the inactivity rate is $5.6 \%$-points, which is also lower than the regression estimate. In both cases, the lower DID estimates result from averaging over the post-reform years (2001-2003) and illustrates the importance of identifying the timing of the effects, which is only possible with the specification of equation (1).

The results presented in Table 4 are also robust to different specifications of the treatment and control groups. ${ }^{16}$ Firstly, dropping the moderately disabled (1-49\%) from the control group does not significantly change the coefficient estimates. Secondly, expanding the treatment group to include those with a degree of disability of $30-49 \%$ results in a reduction in the magnitude of the coefficients on the interacted dummies for being disabled in the post-reform period. In the specification for the probability of unemployment, the coefficient on $\delta_{2002}$ is now equal to -0.053

\footnotetext{
${ }^{16}$ Results are not reported here but are available on request.
} 
in comparison to -0.077 as reported in Table 4 , but it is no longer significant. The coefficient on $\delta_{2003}$ falls to -0.092 from -0.121 but remains significant. Thirdly, we allow for different effects for individuals with a moderate disability (30-49\%) and the severely disabled (50+\%). In this specification, the coefficients for the severely disabled are very similar to those in Table 4, and moreover, the estimates of the interaction terms do not suggest an impact of the PSDA reform for the moderately disabled. As also argued in Section 4, this implies that these two groups are significantly different in terms of their labour market outcomes (conditional on observed variables). Therefore, the assumption of Lechner and Vazquez-Alvarez (2003) to include the moderately disabled with the severely disabled in the treatment group is questionable.

Although we allowed for different impacts of the PSDA reform during the postreform period (2001 -2003) in equation (1), we have so far assumed that the average effect as captured by $\delta_{k}$ is homogeneous in terms of observable characteristics of the individuals. However, it is likely that the impact varies with these traits, in particular, with the degree of disability, age and gender. The coefficient estimates for the heterogeneous interacted terms are reported in Table $5 .{ }^{17}$ In particular, $\delta_{k}\left(X_{i t}\right)$ is now a function of the control variables, such that we estimate the effects for the different sub-groups jointly but allow for different coefficients on the dummy for being disabled $\beta^{j}$, and for the coefficients on the interacted terms $\delta_{k}^{j}$, where $j \in\{A, B\}$ and $A$ and $B$ are the two sub-groups. The sub-groups are based on the degree of disability ( $\mathrm{A}=$ degree of disability between $50-69 \%, \mathrm{~B}=$ degree of disability between 70-89\%), and similarly, for age ( $\mathrm{A}=$ age $25-45, \mathrm{~B}=$ age $=46-55)$ and gender $(\mathrm{A}=$ male, $\mathrm{B}=$ female $)$.

The coefficient estimates for the interaction terms for the severely disabled with a degree of disability from $50-69 \%\left(\delta_{k}^{A}\right)$ and $70-89 \%\left(\delta_{k}^{B}\right)$, are reported in the first two rows of each panel in Table 5. These make up $67.7 \%$ and $32.3 \%$ of all the observations for the severely disabled. Similar to the results reported in Table 4, both sub-groups had a lower probability of unemployment in the years after the reform was enacted. However, only the coefficient on the interaction term for 2003

\footnotetext{
${ }^{17}$ Other coefficient estimates are available on request.
} 
Table 5: Heterogeneous Effects of the PSDA Reform

\begin{tabular}{l|c|c|c|c|c}
\hline \hline A. Dependent variable: employment rate \\
\hline Group & $\delta_{1999}$ & $\delta_{2000}$ & $\delta_{2001}$ & $\delta_{2002}$ & $\delta_{2003}$ \\
\hline Degree 50-69\% & -0.030 & -0.031 & -0.068 & -0.048 & -0.059 \\
Degree 70-89\% & $0.117^{*}$ & 0.066 & 0.097 & $0.131^{*}$ & 0.131 \\
\hline Age 25-45 & 0.065 & -0.027 & -0.053 & 0.026 & 0.001 \\
Age 46-55 & -0.026 & 0.022 & 0.0138 & 0.003 & 0.012 \\
\hline Male & 0.048 & 0.030 & -0.027 & 0.014 & 0.036 \\
Female & -0.022 & -0.047 & -0.024 & -0.016 & -0.049 \\
\hline
\end{tabular}

B. Dependent variable: unemployment rate

\begin{tabular}{l|c|c|c|c|c}
\hline Group & $\delta_{1999}$ & $\delta_{2000}$ & $\delta_{2001}$ & $\delta_{2002}$ & $\delta_{2003}$ \\
\hline $50-69 \%$ & 0.004 & -0.005 & 0.002 & -0.055 & $-0.107^{* *}$ \\
$70-89 \%$ & $-0.146^{*}$ & -0.099 & -0.156 & -0.157 & -0.183 \\
\hline Age 25-45 & -0.054 & 0.005 & 0.023 & -0.041 & $-0.106^{* *}$ \\
Age 46-55 & 0.010 & -0.054 & -0.087 & $-0.114^{*}$ & $-0.142^{* *}$ \\
\hline Male & -0.025 & -0.035 & -0.003 & $-0.108^{*}$ & $-0.151^{* *}$ \\
Female & -0.031 & -0.004 & -0.073 & -0.023 & -0.074 \\
\hline
\end{tabular}

C. Dependent variable: inactivity rate

\begin{tabular}{l|c|c|c|c|c}
\hline Group & $\delta_{1999}$ & $\delta_{2000}$ & $\delta_{2001}$ & $\delta_{2002}$ & $\delta_{2003}$ \\
\hline $50-69 \%$ & 0.034 & 0.045 & $0.081^{*}$ & $0.107^{* *}$ & $0.160^{* *}$ \\
$70-89 \%$ & -0.065 & -0.030 & -0.050 & -0.075 & -0.059 \\
\hline Age 25-45 & -0.030 & 0.036 & 0.049 & 0.010 & 0.085 \\
Age 46-55 & 0.029 & 0.009 & 0.032 & 0.074 & 0.085 \\
\hline Male & -0.041 & -0.011 & 0.028 & 0.075 & 0.085 \\
Female & 0.045 & 0.061 & 0.065 & 0.037 & $0.104^{*}$ \\
\hline \hline
\end{tabular}

Source: GSOEP - 1998-2003, Samples A-F. Number of observations $=60,744$ for employment and inactivity rates specifications; 54,179 for the unemployment rate specification. The coefficients for the sub-groups (degree of disability, age, gender) are jointly estimated as a linear probability model. Each specification includes a dummy for being severely disabled, year dummies, a sex dummy, age, age-squared, years of education, a dummy for being married, dummies for different high school degrees, a dummy whether the individual is satisfied with their health, a dummy for living outside a major city, and a dummy for being in East Germany. 
is significant for individuals with a degree of disability of 50-69\%. In addition to the positive coefficients for the impact of the reform on inactivity, this suggests that the less severely disabled experienced a drop in unemployment, but this came about by these individuals exiting the labour market. In contrast to this group, the severely disabled with a degree of $70-89 \%$ had a increasing probability of employment over 1999-2003 and that the coefficients are significant for both 1999 and 2002.

The next grouping is based on age and in this specification we allow for different effects for two groups in the severely disabled: those who are between 25 and 45 years old $\left(\delta_{k}^{A}\right)$; and those who are between 46 and 55 years old $\left(\delta_{k}^{B}\right)$. These two sub-groups make up $41.5 \%$ and $58.5 \%$ of all observations for the severely disabled. As displayed in the panel $\mathrm{B}$ of Table 5, there is evidence that the probability of unemployment was decreasing in 2002 and 2003 for individuals between 46 and 55 years old, and only in 2002 for the younger age group. Moreover, the effects are much larger for those between 46 and 55. Other coefficients are imprecisely estimated. This provides some indication that the more elderly benefited from the reforms in 2001, though these individuals were in principal too young to take advantage of early retirement schemes, which we consider in Section 5.1.

Finally, we consider the different impact of the reform for males $\left(\delta_{k}^{A}\right)$ and females $\left(\delta_{k}^{B}\right)$. As shown in the panel $\mathrm{C}$ of Table 5 , the effect of the reform on the unemployment rate was stronger for males with severe disabilities than for females. The different estimates displayed in the three panels of Table 5 indicate that if the reform led to a decrease in the unemployment rate for the severely disabled after 2001, it was the most effective for males and the more elderly. Moreover, this was achieved by an improvement in the probability of employment for the more disabled (70-89\%) but also by a higher probability of exiting the labour force for the less severely disabled (50-69\%).

To further investigate the effects of the reform on labour market participation, we consider the impact on transition rates, particularly on the outflows from unemployment. However, as evident in Table 3, the number of observations in the cells for people with disabilities is very low. Nonetheless, we can repeat the estimation of equation (1) where the outcome variables are now the transition rates from employ- 
ment, unemployment, and inactivity. This can be denoted as: $Y_{i t}^{j m}=1$ if $L F S_{i t}=j$ and $L F S_{i, t+1}=m$, and 0 otherwise. LFS stands for the labour force state, such that $j, m \in\{$ employed, unemployed, inactive $\}$. As before we estimate the impact of the reform on the transition rates $Y^{j m}$ as a linear probability model. In Table 6 we only report the coefficient estimates for the interacted terms $\left(\lambda_{k} \cdot d_{i}\right)$, and since we are looking at the transitions from one year to the next, the coefficients that should identify the impact of the reform are $\delta_{2001}$ and $\delta_{2002}$. However, most of the coefficients are mostly imprecisely estimated, which is not surprising given the small cell sizes. There is, however, some evidence that probability of remaining unemployed was decreasing over the period 2002-2003 for people with severe disabilities. There is no suggestion that the reform had an impact on the flows from unemployment to either employment or out of the labour market. Secondly, the rate of flows from employment to unemployment was decreasing for the whole period 1999-2003, but the coefficient on the interaction term is only significant for the transition from 2002 to 2003. Finally, inactivity was increasingly becoming an absorbing state, particularly from 2001.

Together with the evidence from Table 4, these results imply that, while the unemployment rate decreased for the severely disabled after the reform to the PSDA, it appears that this was achieved by an increase in the rate of inactivity. This development may have been influenced by changes in benefit eligibility; however, since the sample is restricted to the working age (25-55), it is unlikely to be the result of early retirement.

\subsection{Incentives to retire}

The sample used for the above results is restricted to individuals of working age (2555), though as noted by Bundesministerium für Gesundheit und Soziale Sicherung (2003), the age group 55-60 were one of the main beneficiaries of the reform. According to the official figures, the number of unemployed people with severe disabilities fell by 45,000 from October 1999 to October 2002. 35,649 individuals or around 78\% of this total were between 55 and 65 years old (Bundesministerium für Gesundheit und Soziale Sicherung 2003). One explanation for this outcome is the incentives for 
Table 6: Impact of PSDA Reform on Transition Rates

\begin{tabular}{l|c|c|c}
\hline \hline & \multicolumn{3}{|c}{ Dependent Variable } \\
\hline Variable & $Y^{11}$ & $Y^{12}$ & $Y^{13}$ \\
\hline$\delta_{1999}$ & -0.003 & -0.020 & -0.012 \\
$\delta_{2000}$ & -0.041 & -0.026 & 0.008 \\
$\delta_{2001}$ & -0.036 & -0.027 & -0.005 \\
$\delta_{2002}$ & -0.038 & $-0.039^{* *}$ & 0.015 \\
\hline & $Y^{21}$ & $Y^{22}$ & $Y^{23}$ \\
\hline$\delta_{1999}$ & 0.005 & 0.003 & -0.004 \\
$\delta_{2000}$ & -0.006 & 0.009 & -0.011 \\
$\delta_{2001}$ & -0.002 & -0.029 & 0.017 \\
$\delta_{2002}$ & 0.002 & $-0.054^{* *}$ & 0.008 \\
\hline & $Y^{31}$ & $Y^{32}$ & $Y^{33}$ \\
\hline$\delta_{1999}$ & -0.020 & 0.020 & 0.035 \\
$\delta_{2000}$ & 0.003 & -0.003 & $0.062^{*}$ \\
$\delta_{2001}$ & -0.010 & 0.020 & $0.080^{* *}$ \\
$\delta_{2002}$ & 0.007 & -0.003 & $0.097^{* *}$ \\
\hline \hline
\end{tabular}

Source: GSOEP - 1998-2003, Samples A-F. Number of observations $=45,893$. All specifications are estimated as a linear probability model and include as control variables a dummy for being severely disabled, year dummies, a sex dummy, age, agesquared, years of education, a dummy for being married, dummies for different high school degrees, a dummy whether the individual is satisfied with their health, a dummy for living outside a major city, and a dummy for being in East Germany. *** - $1 \%$ significance level, ${ }^{* *}$ - $5 \%$ significance level, ${ }^{*}$ - $10 \%$ significance level.

early retirement in Germany. In this regard, it is likely that many elderly people with severe disabilities did not exit unemployment for employment, but rather into early retirement. Moreover, the impact of the PSDA reform coincided with changes to the eligibility for early retirement, which also came into effect after 2001. Until 2001 people with severe disabilities were able to retire at 60. After 2001 this age 
threshold was increased in steps, and as of January 2004, it stands at 63 . There are two exceptions to this post-2001 rule: firstly, those born before January 1951 were still able go into pension at 60 , however, with a $10.8 \%$ reduction in the pension; secondly, those born before 16th of November, 1950 and who were already severely disabled as of 16th of November, 2000, were able to retire at 60 without any reduction in payments. ${ }^{18}$ These changes imply that after 2001 it became increasingly difficult for the severely disabled to retire early, and therefore, it is possible that these changes encouraged these individuals, who were approaching retirement, to take the opportunity earlier than would have occurred under the old system of eligibility rules.

Restricting the sample to those between 56 and 65 allows us to evaluate the effects of the PSDA reform in 2001 on the same labour market outcomes as investigated for the working-age sample: the employment; unemployment; inactivity; and transition rates. For this age group we have 16,284 person-year observations, of which 1,599 or $9.8 \%$ are for people with permanent and severe disabilities. In this sub-sample, $41 \%$ of the non-disabled are employed compared to only $16.4 \%$ for the severely disabled. This is a consequence of the inactive status of the majority of people with severe disabilities (78.8\%), compared to only $49 \%$ for the non-disabled. There is much less of a difference between the unemployment rates of these two group: $19 \%$ for the severely disabled versus $23 \%$ for the non-disabled. The estimates of the coefficients $\delta_{k}$ for the years 1999 to 2003 are displayed in Table $7 . Y^{j}$ is defined as above. In contrast to the results for the working-age population, there is no longer any evidence that the probability of unemployment for the age group 56-65 decreased after the PSDA reform. There is, however, a fall in the probability of employment for the severely disabled by 6.8\%-points in 2002 and 9.6\%-points in 2003. This is also reflected in the lower probability of remaining in the employment state during this period. Looking at the third row of Table 7 , the coefficient estimates indicate that the probability of inactivity increased in 2002 and 2003, though only the latter is significant. Thus, there is evidence that the severely disabled in this age group exited the labour market after the PADA reform. To check whether this was the

\footnotetext{
${ }^{18}$ For these figures, see the edition of Die Welt on 19.01.04.
} 
Table 7: Effects of the PSDA Reform on the Age Group 56-65

\begin{tabular}{|c|c|c|c|c|c|c|}
\hline & \multicolumn{5}{|c|}{ Coefficient } & \multirow[b]{2}{*}{ No. of Obs. } \\
\hline $\begin{array}{l}\text { Dependent } \\
\text { Variable }\end{array}$ & $\delta_{1999}$ & $\delta_{2000}$ & $\delta_{2001}$ & $\delta_{2002}$ & $\delta_{2003}$ & \\
\hline E-rate & 0.018 & 0.003 & -0.033 & $-0.068^{*}$ & $-0.096^{* * *}$ & 15,855 \\
\hline U-rate & 0.011 & 0.024 & 0.051 & 0.079 & 0.054 & 7,558 \\
\hline IA-rate & -0.033 & -0.034 & 0.003 & 0.031 & $0.067^{*}$ & 15,855 \\
\hline$Y^{11}$ & -0.012 & -0.016 & $-0.093^{* * *}$ & $-0.100 * * *$ & - & 11,076 \\
\hline$Y^{12}$ & 0.010 & 0.000 & 0.010 & -0.002 & - & 11,076 \\
\hline$Y^{13}$ & -0.004 & 0.006 & 0.007 & 0.000 & - & 11,076 \\
\hline$Y^{21}$ & -0.001 & -0.001 & 0.004 & 0.001 & - & 11,076 \\
\hline$Y^{22}$ & 0.014 & 0.014 & 0.011 & 0.024 & - & 11,076 \\
\hline$Y^{23}$ & 0.011 & 0.020 & 0.024 & 0.017 & - & 11,076 \\
\hline$Y^{31}$ & $0.025^{* *}$ & 0.010 & $0.022^{*}$ & $0.023^{*}$ & - & 11,076 \\
\hline$Y^{32}$ & -0.012 & -0.005 & 0.003 & -0.010 & - & 11,076 \\
\hline$Y^{33}$ & -0.031 & -0.022 & 0.013 & 0.042 & - & 11,076 \\
\hline Retired & -0.030 & -0.035 & -0.027 & 0.013 & 0.006 & 15,855 \\
\hline
\end{tabular}

Source: GSOEP - 1998-2003, Samples A-F. All dependent variables are binary. Erate $=$ employment rate, $\mathrm{U}$-rate $=$ unemployment rate, IA-rate $=$ inactivity rate All specifications are estimated as a linear probability model and include as control variables a dummy for being severely disabled, year dummies, a sex dummy, age, age-squared, years of education, a dummy for being married, dummies for different high school degrees, a dummy whether the individual is satisfied with their health, a dummy for living outside a major city, and a dummy for being in East Germany. *** - $1 \%$ significance level, ${ }^{* *}-5 \%$ significance level, $*$ - $10 \%$ significance level.

consequence of an increase in early retirements, we estimate the effects of the reform on the probability of receiving an old age or invalid pension. As shown in the last row of Table 7, there is no significant difference in the probability of having a pension after the reform. To investigate this further, we also check whether the exit rates 
from the labour market to retirement changed over this period. However, none of the coefficients for these specifications are significantly different from zero, but again this is likely to result from the small cell sizes. ${ }^{19}$

\section{Conclusion}

With the persistence in the poor labour market performance of people with disabilities, governments have introduced policy measures to improve this situation. The evaluation of a reform to the People with Severe Disabilities Act (PSDA) in Germany in 2001 provides some insight into the effectiveness of one type of legislation, that which enforces the employment of people with disabilities through a quota and a combination of levies for non-compliance. The Government claimed that this reform was responsible for a reduction in the number of unemployed people with severe disabilities by $25 \%$ or 45,000 individuals. While this claim is supported by both the aggregate statistics and the results using German individual data, there is evidence that this was achieved by the severely disabled exiting out of the labour market, rather than entering paid employment. Moreover, the recent increase in the unemployment for this group suggests that the benefits of the reform were at best temporary. These results indicate that the adjustments to the financial incentives in the legislation were not strong enough to increase demand for these workers, which is not surprisingly given the small size of the fines for non-compliance and the poor economic conditions at the time of the reform.

It is important to understand how policies affect the labour market participation of people with disabilities not only because of the current situation for this group, but also because an ageing population in most OECD countries will lead to an increase in the prevalence of disabilities. With this demographic change, governments have to rethink their policies which aim to integrate people with disabilities into the labour force, including how financial incentives are used to improve the participation of the disabled.

\footnotetext{
${ }^{19}$ Results are available from the author on request.
} 


\section{References}

Acemoglu, D., And J. Angrist (2001): "Consequences of Employment Protection? The Case of Americans with Disabilities Act," Journal of Political Economy, $109,915-957$.

Bundesministerium Für Gesundheit und Soziale Sicherung (2003): "Bericht der Bundesregierung nach $§ 160$ des Neunten Buches Sozialgesetzbuch (SGB IX) über die Beschäftigungssituation schwerbehinderter Menschen,” .

DeLeire, T. (2000): "The Wage and Employment Effects of the Americans with Disability Act," Journal of Human Resources, 35, 693-715.

Delsen, L. (1996): "Employment Opportunities for the Disabled," in International Handbook of Labour Market Policy and Evaluation, ed. by G. Schmid, J. O'Reilly, and K. Schömann, pp. 520-550, Cheltenham, UK. Edward Elgar.

Georg, A., And M. Stackelbeck (1997): "Case Studies on Employment of People with Disabilities in Small and Medium Sized Enterprises," European Foundation for the Improvement of Living and Working Conditions Working Paper, $\mathrm{WP} / 97 / 60 / \mathrm{EN}$.

Kölling, A., C. Schnabel, and J. Wagner (2001): "Bremst das Schwerbehindertengesetz die Arbeitsdynamik in Kleinbetrieben? - Eine empirische Untersuchung mit Daten des IAB-Betriebspanels," Beiträger zur Arbeitsmarkt- und Berufsforschung, 251, 183-209.

Lechner, M., and R. Vazquez-Alvarez (2003): "The Effect of Disability on Labour Market Outcomes in Germany: Evidence from Matching," IZA Discussion Paper, 967.

OECD (2003): Transforming Disability Into Ability. OECD, Paris.

O’Reilly, A. (2003): "The Right to Decent Work of Persons with Disabilities," ILO-IFP/Skills Working Paper, 14. 
7 Appendix 


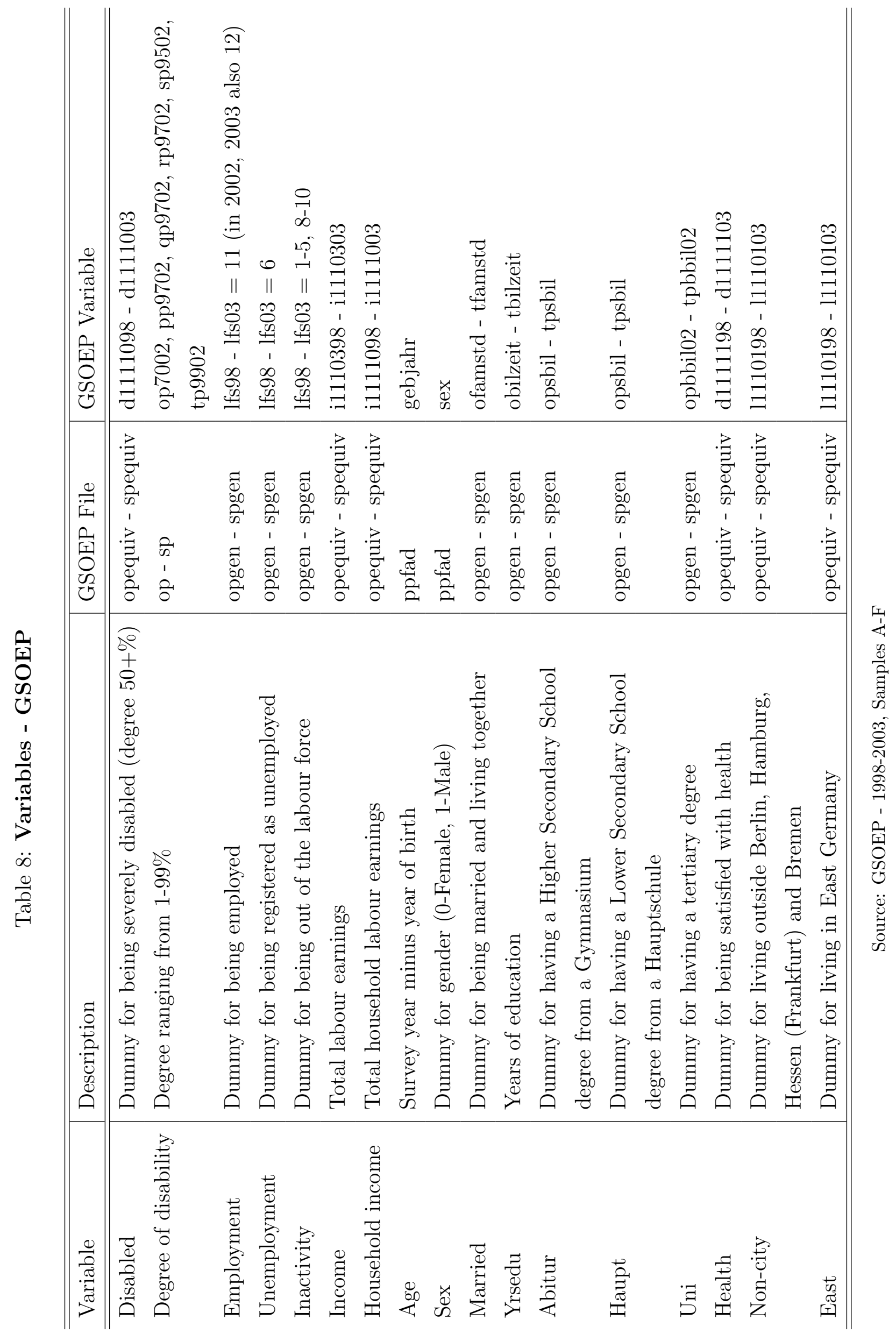

